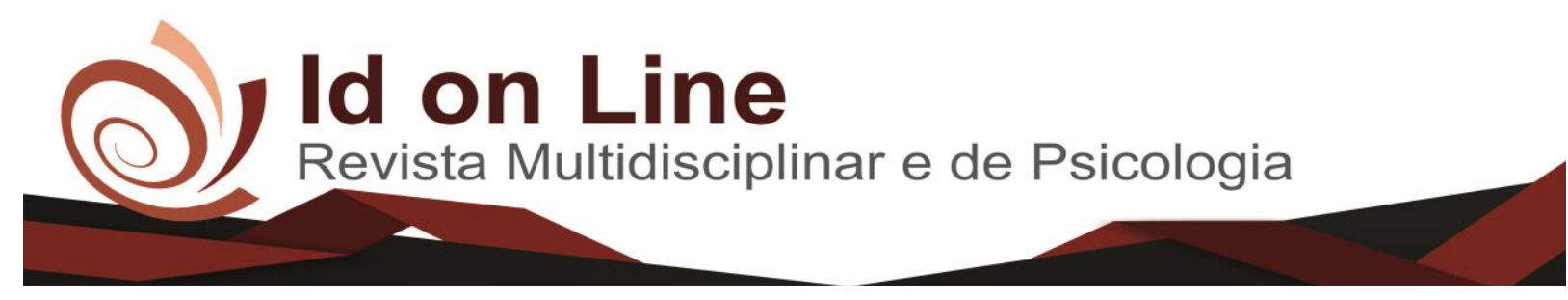

Artigo de Revisão

\title{
Radiofrequência no Tratamento de Rugas: Uma Revisão Integrativa
}

Patriciana Rodrigues da Silva ${ }^{1}$; Adna Gorette Ferreira Andrade ${ }^{2}$; Juliana Braga Facchinetti ${ }^{3}$

\begin{abstract}
Resumo: O objetivo desse estudo foi revisar a literatura científica em relação os efeitos da radiofrequência no tratamento das rugas. Foram realizadas uma busca nas bases de LILACS, SciELO, MEDLINE, PUBMED, no período de outubro e novembro de 2017, selecionando-se 7 artigos publicados entre Janeiro de 2010 a Setembro de 2017, artigos originais, que abordavam a temática radiofrequência não ablativa como tratamento de rugas e flacidez facial associados ou não a outras terapias. Os descritores utilizados foram "radiofrequência"; "rugas"; "rejuvenescimento"; "flacidez tissular"; "envelhecimento da pele". Foi possível concluir que a técnica é eficaz na atenuação e melhora das rugas e flacidez, com melhora do aspecto visual e satisfação pessoal, quando utilizada com um intervalo de sessões semanal ou mensal, porém sugerem-se que novas pesquisas sejam realizadas a fim de esclarecer tais questões e ampliar os conhecimentos já existentes.
\end{abstract}

Palavras-Chaves: Radiofrequência; Rugas; Rejuvenescimento; Flacidez tissular, Envelhecimento da pele.

\section{Radiofrequency in the Treatment of Wrinkles: An Integrative Review}

\begin{abstract}
The objective this study was to review the scientific literature regarding the radiofrequency effects in the wrinkles treatment. A study was carried out based on LILACS, SciELO, MEDLINE and PUBMED, beetween October, 2017 and November, 2017. Seven published papers between January, 2010 and September, 2017 was selected. These original papers, that approached the subject of non-abrative radiofrequency as treatment of wrinkles and facial flaccidity associated or not with other therapies. The descriptors "radiofrequency"; "wrinkles"; "rejuvenation"; "tissue flaccidity"; "aging of the skin" were used. It was possible to conclude that the technique is effective in attenuating and improving wrinkles and facial flaccidity. There were improving the visual appearance and personal satisfaction, when accomplish weekly or monthly sessions. However it is suggested that further research be performed in order to clarify and extend existing knowledge.
\end{abstract}

Keyword: Radio frequency; Wrinkles; Rejuvenation; Tissue Flaccidity, Skin Aging.

\footnotetext{
${ }^{1}$ Discente Graduanda do Curso de Fisioterapia pela Faculdade Independente do Nordeste/ FAINOR; Vitória da Conquista BA, Brasil; patriciana.anage@gmail.com

2 Fisioterapeuta, Docente da Faculdade Independente do Nordeste /FAINOR Vitória da Conquista/BA, Brasil; goretteandrade@gmail.com

${ }^{3}$ Fisioterapeuta, Docente da Faculdade Independente do Nordeste /FAINOR Vitória da Conquista/BA, Brasil. Especialista em Fisioterapia Dermato Funcional pela Universidade Gama Filho; julianafacchinetti@ hotmail.com
} 


\section{Introdução}

O envelhecimento cutâneo é um processo contínuo e inevitável, entretanto, quando o indivíduo atinge os 30 anos de idade, os sinais deste processo como as rugas e a flacidez ficam mais aparentes (MACHADO; CAVALIÉRE, 2010). Estudos apontam que o envelhecimento pode ser desencadeado por fatores intrínsecos ou extrínsecos. Os fatores intrínsecos apresentam relação com a idade e a genética, logo, se torna natural e inevitável. Os fatores extrínsecos se relacionam com ambiente, exposição aos raios ultravioletas, a poluição, má alimentação, estresse e tabagismo, ou seja, oriundo de maus hábitos ao longo da vida (TESTON; NARDINO; PIVATO, 2010).

Segundo Macedo e Tenório (2015), o envelhecimento torna a pele mais delgada, enrugada e ressecada. As fibras colágenas da derme tornam-se mais grossas, as fibras elásticas perdem parte de sua elasticidade e há um decréscimo gradual da gordura depositada no tecido subcutâneo. Essas alterações propiciam uma menor velocidade de troca de oxigenação dos tecidos, maior desidratação da pele, tornando-a menos flexível, tendo como consequências o aparecimento de flacidez e das rugas.

As rugas são sulcos ou pregas da superfície da pele e correspondem ao sinal mais aparente do envelhecimento, elas podem ser classificadas como superficiais ou profundas. As superficiais são aquelas que desaparecem quando realizado o estiramento da pele, já as profundas não sofrem alteração mesmo quando a pele é estirada. As rugas ainda podem ser classificadas como estáticas, dinâmicas ou gravitacionais. As estáticas são consequências da fadiga das estruturas que constituem a pele, em decorrência da repetição dos movimentos e aparecem mesmo na ausência deles. As dinâmicas surgem como consequência de movimentos repetitivos da expressão facial, aparecem apenas com o movimento, já as rugas gravitacionais são consequentes da flacidez do envelhecimento facial (SOUSA, 2016).

De acordo Sousa (2013), as rugas podem ser diferenciadas quanto ao grau, sendo de $1^{\circ}$ grau, quando aparecem na segunda década de vida; de $2^{\circ}$ grau, quando aparecem na terceira e quarta década de vida; $3^{\circ}$ grau; quando ocorrem na quinta década em diante. Além do aspecto inestético aparente, as rugas podem causar distúrbios psicológicos, emocionais, comprometendo a vida social, o que influenciará na qualidade de vida do indivíduo (SOUZA et al., 2007). 
Novas tecnologias têm surgido nos últimos anos para o tratamento das linhas de expressão e rugas, o que possibilita uma maior oferta de opções para melhorar o aspecto (FONTOURA, 2009). Existe, entretanto, uma preferência por procedimentos não abrativos, como por exemplo, o tratamento coma radiofrequência.

A radiofrequência é um tipo de corrente de alta frequência que converte uma energia eletromagnética de elevada frequência em calor. Seu objetivo é remodelar as fibras de colágeno, este recurso terapêutico promove a reabsorção dos líquidos intercelulares excessivos, estimulando ganho nutricional de oxigênio, nutrientes e oligoelementos, melhora as toxinas, ocorre uma vascularização na derme, vasodilatação e hiperemia. Aumenta a produção de fibras elásticas dos tecidos ricos em colágeno, atuando nos fibroblastos e em demais células, estimula a neocolagênogenese, minimiza a flacidez e a ptose, realiza um relaxamento da musculatura (BORGES, 2010).

Diante disso, é importante conhecer melhor as formas de aplicação, parâmetros, intervalo de sessões e protocolos utilizados com a radiofrequência assim como, os respectivos resultados obtidos no tratamento das rugas. Desta forma, torna-se fundamental desenvolver uma revisão e compilação de informações sobre o assunto que poderão servir de evidência para tratamentos mais eficazes. Neste sentido, o presente estudo procurou revisar a literatura de forma integrativa sobre a utilização da radiofrequência no tratamento de rugas.

\section{Metodologia}

Trata-se de uma revisão integrativa da literatura, a qual segundo Mendes, Silveira e Galvão (2008) inclui a análise de pesquisas relevantes que dão suporte para a tomada de decisão e a melhoria da prática clínica, também possibilitam a síntese do estado do conhecimento de um determinado assunto, além de apontar lacunas do conhecimento que precisam ser preenchidas com a realização de novos estudos. Este método de pesquisa permite o resumo de múltiplos estudos publicados e possibilita conclusões gerais a respeito de uma particular área de estudo. É um método valioso para profissionais da área de saúde em geral, pois muitas vezes os profissionais não têm tempo para realizar a leitura de todo o conhecimento científico disponível, além da dificuldade para realizar a análise crítica dos mesmos. 
Para a elaboração deste trabalho foram consultados artigos científicos através de busca em base de dados como Scielo, Bireme, Lilacs, Medline e Pubmed no período de Outubro e Novembro de 2017, buscando-se artigos originais publicados no período de Janeiro de 2010 a Setembro de 2017. Os descritores utilizados foram "radiofrequência"; "rugas"; "rejuvenescimento"; "flacidez tissular"; "envelhecimento da pele". Estes descritores foram utilizados separadamente e também com as seguintes combinações: (tw: (radiofrequência)) AND (tw: (rugas)).

Foram incluídos estudos publicados entre os anos de 2010 a 2017, artigos originais, produções que abordavam a radiofrequência não abrasiva como tratamento de rugas e flacidez faciais associados ou não a outras terapias. Foram excluídas da coleta produções científicas em língua estrangeira, produções que não estavam disponíveis em versão completa e artigos de revisão.

Para elaboração da pesquisa foi realizada inicialmente a definição do problema/objeto do estudo, em seguida foram definidos os critérios de inclusão e exclusão para que assim pudesse ser iniciada a busca dos estudos, a avaliação crítica dos estudos e coleta de dados. Finalmente foi desenvolvida a síntese dos dados e discussão dos resultados.

Para a coleta de dados, os itens foram elaborados em forma de tabela de resultados contendo os seguintes itens: Identificação do artigo: Título, autores, ano de publicação, orientação metodológica, objetivos, população estudada e resultados obtidos.

Foram encontrados 221 artigos, utilizando os descritores nas bases de dados - Lilacs; Medline; Scielo; Pubmed. Após a realizada a busca atendendo aos critérios de inclusão e exclusão, foram identificados sete artigos de grande relevância à pesquisa. Estes artigos foram lidos criteriosamente e utilizados como resultados deste estudo. 


\section{Resultados}

Tabela 1. Distribuição dos sete estudos selecionados sobre radiofrequência no tratamento de rugas e flacidez facial e as suas características metodológicas, objetivos e resultados encontrados.

\begin{tabular}{|c|c|c|c|c|c|}
\hline Título & Ano & $\begin{array}{c}\text { Orientação } \\
\text { metodológica }\end{array}$ & Objetivo & Participantes & $\begin{array}{l}\text { Principais } \\
\text { resultados }\end{array}$ \\
\hline $\begin{array}{l}\text { Estudo dos efeitos } \\
\text { da radiofrequência } \\
\text { no tratamento facial } \\
\text { em mulheres de } 50 \text { e } \\
60 \text { anos }\end{array}$ & $\begin{array}{l}\text { Busnardo; Azevedo, } \\
2012 .\end{array}$ & $\begin{array}{l}\text { Estudo exploratório, } \\
\text { descritivo com } \\
\text { abordagem } \\
\text { qualitativo e } \\
\text { quantitativo. }\end{array}$ & $\begin{array}{l}\text { Avaliar e } \\
\text { quantificar os } \\
\text { efeitos de um } \\
\text { programa de } \\
\text { tratamento de } 8 \\
\text { semanas de } \\
\text { radiofreqüência } \\
\text { Spectra® na } \\
\text { melhora das } \\
\text { rugas, da } \\
\text { tonicidade, do } \\
\text { aspecto da pele e } \\
\text { do contorno facial. }\end{array}$ & $\begin{array}{l}\text { O estudo utilizou } \\
\text { uma amostra de } 16 \\
\text { mulheres com IMC } \\
\text { inferior a } 29,9 \\
\mathrm{~kg} / \mathrm{m}^{2}, \\
\text { não tabagistas, } \\
\text { sedentárias, com } \\
\text { fototipo II e III } \\
\text { segundo Fitzpatrick. } \\
\text { Foram divididas } \\
\text { igualmente em dois } \\
\text { grupos, sendo A } \\
\text { experimental e o } \\
\text { grupo B controle. }\end{array}$ & $\begin{array}{l}\text { Após a } \\
\text { reavaliação } \\
\text { verificou-se } \\
\text { uma diferença } \\
\text { significativa } \\
\text { (p=0,017) do } \\
\text { grupo } \\
\text { experimento pré } \\
\text { e pós-rugas } \\
\text { frontal com } \\
\text { redução de } 20 \% \\
\text { no número de } \\
\text { rugas do grupo } \\
\text { experimental. }\end{array}$ \\
\hline $\begin{array}{l}\text { Radiofrequência } \\
\text { aplicada em rugas } \\
\text { periobiculares: } \\
\text { Avaliação de um } \\
\text { novo protocolo }\end{array}$ & Pimentel, 2014. & $\begin{array}{l}\text { Estudo } \\
\text { experimental, não } \\
\text { probabilístico, } \\
\text { longitudinal. }\end{array}$ & $\begin{array}{l}\text { Avaliar um } \\
\text { protocolo proposto } \\
\text { para o tratamento } \\
\text { de rugas } \\
\text { periorbiculares } \\
\text { através de sessões } \\
\text { semanais de } \\
\text { aplicação de RF em } \\
\text { idosos. }\end{array}$ & $\begin{array}{l}\text { A amostra foi } \\
\text { composta por14 } \\
\text { idosos usuários de } \\
\text { uma clínica de } \\
\text { Fisioterapia, com } \\
\text { idade entre } 60 \text { a } 75 \\
\text { anos, com rugas } \\
\text { peiriorbiculares. } \\
\text { Foram excluídos } \\
\text { indivíduos } \\
\text { tabagistas que } \\
\text { estivesse em uso de } \\
\text { corticóides e } \\
\text { antiinflamatórios } \\
\text { esteróidais bem } \\
\text { como o uso de } \\
\text { cosméticos e ácidos } \\
\text { dermatológico } \\
\text { durante a pesquisa. } \\
\text { Fora divididos em } \\
\text { dois grupos, grupo } \\
\text { placebo(GP) } \\
\text { composta por cinco } \\
\text { mulheres e dois } \\
\text { homens e grupo } \\
\text { experimental(GE) } \\
\text { composta por sete } \\
\text { mulheres. }\end{array}$ & $\begin{array}{l}\text { Com relação à } \\
\text { percepção das } \\
\text { rugas pelos } \\
\text { voluntários do } \\
\text { GE em relação } \\
\text { ao GP relataram } \\
\text { insatisfação } \\
\text { antes do } \\
\text { tratamento } \\
\text { variando de } \\
\text { moderado a } \\
\text { muitíssimo } \\
\text { insatisfeita e } \\
\text { após o } \\
\text { tratamento a } \\
\text { reavaliação } \\
\text { constatou que o } \\
\text { grau de } \\
\text { insatisfação } \\
\text { reduziu } \\
\text { variando de } \\
\text { pouco a } \\
\text { moderado } \\
\text { insatisfeito. O } \\
\text { grau de } \\
\text { satisfação dos } \\
\text { participantes } \\
\text { com o } \\
\text { tratamento } \\
\text { variou de } \\
\text { moderado a } \\
\text { ótimo. }\end{array}$ \\
\hline $\begin{array}{l}\text { Análise de um } \\
\text { protocolo de } \\
\text { laserterapia de baixa } \\
\text { potência e } \\
\text { radiofrêquencia no } \\
\text { tratamento de rugas } \\
\text { em idosos }\end{array}$ & Sousa, 2013. & $\begin{array}{l}\text { Estudo experimental } \\
\text { e longitudinal. }\end{array}$ & $\begin{array}{l}\text { Analisar um } \\
\text { protocolo de } \\
\text { laserterapia } \\
\text { associada à } \\
\text { radiofrequência } \\
\text { para o tratamento } \\
\text { de rugas }\end{array}$ & $\begin{array}{l}\text { A amostra foi } \\
\text { constituída por } 14 \\
\text { voluntários, com } \\
\text { faixa etária entre } 60 \\
\text { e } 70 \text { anos, que } \\
\text { apresentavam rugas } \\
\text { superficiais ou }\end{array}$ & $\begin{array}{l}\text { O protocolo } \\
\text { utilizado não } \\
\text { demonstrou } \\
\text { resultados } \\
\text { visuais } \\
\text { aceitáveis que o } \\
\text { habilitasse com }\end{array}$ \\
\hline
\end{tabular}




\begin{tabular}{|c|c|c|c|c|c|}
\hline & & & $\begin{array}{l}\text { periorbiculares em } \\
\text { idosos, por meio de } \\
\text { fotografias e } \\
\text { escalas para rugas, } \\
\text { sendo observados } \\
\text { os aspectos } \\
\text { quantitativos e } \\
\text { qualitativos. }\end{array}$ & $\begin{array}{l}\text { profundas na região } \\
\text { periorbicular, foram } \\
\text { excluídos da } \\
\text { pesquisa indivíduos } \\
\text { ou que fazem uso } \\
\text { de cordicoides e } \\
\text { antiiflamatorios não } \\
\text { esteriodais, uso de } \\
\text { cosméticos ou } \\
\text { ácidos } \\
\text { dermatológicos e } \\
\text { pacientes } \\
\text { acometidos ou } \\
\text { com suspeita de } \\
\text { glaucoma . Os } \\
\text { voluntários foram } \\
\text { divididos em um } \\
\text { grupo experimental } \\
\text { e um grupo placebo. }\end{array}$ & $\begin{array}{l}\text { total garantia } \\
\text { para ser } \\
\text { utilizado no } \\
\text { tratamento das } \\
\text { rugas } \\
\text { periorbiculares } \\
\text { em idosos, } \\
\text { entretanto } \\
\text { obteve uma } \\
\text { percepção dos } \\
\text { usuários quanto } \\
\text { a melhora das } \\
\text { rugas, essa } \\
\text { satisfação pode } \\
\text { ser atribuída a } \\
\text { outros fatores, e } \\
\text { não a eficácia } \\
\text { real do } \\
\text { tratamento, já } \\
\text { que a maioria se } \\
\text { sentia satisfeita } \\
\text { pelo simples } \\
\text { fato de estar } \\
\text { sendo atendida e } \\
\text { estar se } \\
\text { cuidando. }\end{array}$ \\
\hline $\begin{array}{l}\text { Radiofrequência no } \\
\text { juvenescimento facial }\end{array}$ & $\begin{array}{l}\text { Silva; Hansen ; } \\
\text { Sturzenegger, (2012) }\end{array}$ & $\begin{array}{l}\text { Pesquisa } \\
\text { experimental, } \\
\text { qualitativa. }\end{array}$ & $\begin{array}{l}\text { Avaliar o uso da } \\
\text { radiofrequência no } \\
\text { rejuvenescimento } \\
\text { facial. }\end{array}$ & $\begin{array}{l}\text { Cinco voluntárias } \\
\text { do gênero feminino, } \\
\text { com idade entre } 35 \\
\text { a } 55 \text { anos, que se } \\
\text { adequaram aos } \\
\text { critérios de seleção } \\
\text { apresentando: } \\
\text { flacidez cutânea e } \\
\text { linhas de expressão } \\
\text { aparente no rosto } \\
\text { que se } \\
\text { incomodavam com } \\
\text { o envelhecimento e } \\
\text { não tinham } \\
\text { nenhuma contra } \\
\text { indicação ao } \\
\text { tratamento. }\end{array}$ & $\begin{array}{l}\text { Pode- se notar } \\
\text { uma melhora } \\
\text { significativa no } \\
\text { aspecto geral da } \\
\text { pele de todas as } \\
\text { voluntarias, } \\
\text { tendo evidencia } \\
\text { maior na B onde } \\
\text { houve uma } \\
\text { melhora na } \\
\text { significativa na } \\
\text { região frontal e } \\
\text { na região } \\
\text { nasolabial. } \\
\text { Houve as } \\
\text { diminuição da } \\
\text { profundidade } \\
\text { das rugas em } \\
\text { todas as a } \\
\text { voluntarias com } \\
\text { bom resultado } \\
\text { em relação a } \\
\text { flacidez na } \\
\text { região lateral da } \\
\text { face. }\end{array}$ \\
\hline $\begin{array}{l}\text { Efeitos da } \\
\text { radiofrequência no } \\
\text { tratamento de } \\
\text { flacidez facial em } \\
\text { mulheres. }\end{array}$ & $\begin{array}{l}\text { Nienkoetter; Helmann, } \\
\text { Gonçalves (2012). }\end{array}$ & $\begin{array}{l}\text { Pesquisa quase- } \\
\text { experimental de } \\
\text { caráter qualitativo. }\end{array}$ & $\begin{array}{l}\text { O objetivo desse } \\
\text { estudo foi verificar } \\
\text { os efeitos da } \\
\text { radiofrequência } \\
\text { Bipolar da marca } \\
\text { CECBRA no } \\
\text { tratamento de } \\
\text { flacidez facial. }\end{array}$ & $\begin{array}{l}\text { Participaram da } \\
\text { pesquisa } 10 \\
\text { mulheres com } \\
\text { queixa de flacidez } \\
\text { facial. Os critérios } \\
\text { de exclusão } \\
\text { foram: Idade } \\
\text { inferior a } 35 \text { anos e } \\
\text { superior a } 45 \text { anos } \\
\text { de idade, que } \\
\text { não apresentavam } \\
\text { queixas de }\end{array}$ & $\begin{array}{l}\text { Os resultados } \\
\text { apontaram } \\
\text { redução da } \\
\text { flacidez facial, } \\
\text { linhas de } \\
\text { expressão rugas } \\
\text { e melhora na } \\
\text { coloração da } \\
\text { pele, em todas as } \\
\text { participantes, as } \\
\text { mesmas também } \\
\text { relataram }\end{array}$ \\
\hline
\end{tabular}




\begin{tabular}{|c|c|c|c|c|c|}
\hline & & & & $\begin{array}{l}\text { flacidez facial, } \\
\text { mulheres com } \\
\text { histórico de tecido } \\
\text { maligno, que } \\
\text { apresentavam lesão } \\
\text { dérmica } \\
\text { facial, que } \\
\text { realizaram cirurgia } \\
\text { plástica facial, que } \\
\text { realizavam } \\
\text { outro tratamento } \\
\text { dermatofuncional } \\
\text { facial e que } \\
\text { apresentavam } \\
\text { contra indicações } \\
\text { para utilização da } \\
\text { radiofrequência. }\end{array}$ & $\begin{array}{l}\text { satisfação } \\
\text { quanto ao } \\
\text { tratamento. }\end{array}$ \\
\hline $\begin{array}{l}\text { Efetividade da } \\
\text { radiofrequiência no } \\
\text { tratamento facial de } \\
\text { voluntárias } \\
\text { tabagistas e não } \\
\text { tabagistas }\end{array}$ & Marchi, et al (2016) & $\begin{array}{l}\text { Pesquisa } \\
\text { experimental de } \\
\text { abordagem } \\
\text { qualitativa }\end{array}$ & $\begin{array}{l}\text { O objetivo desse } \\
\text { estudo foi avaliar os } \\
\text { efeitos do tratamento } \\
\text { facial com } \\
\text { radiofrequência em } \\
\text { pele de voluntárias } \\
\text { tabagistas e não- } \\
\text { tabagistas. }\end{array}$ & $\begin{array}{l}\text { Participaram do } \\
\text { estudo oito } \\
\text { voluntarias do sexo } \\
\text { feminino, } 04 \\
\text { tabagistas e } 04 \\
\text { não-tabagistas, } \\
\text { com idade entre } 47 \\
\text { e } 53 \text { anos, com } \\
\text { fototipo II e III, na } \\
\text { escala de } \\
\text { Fitzpatrik, sem } \\
\text { histórico de } \\
\text { patologias ou } \\
\text { tratamentos } \\
\text { recentes e sem } \\
\text { restrições } \\
\text { dietéticas }\end{array}$ & $\begin{array}{l}\text { Verificou se } \\
\text { como resultado } \\
\text { a redução da } \\
\text { extensão de } \\
\text { rugas do canto } \\
\text { externo dos } \\
\text { olhos e face } \\
\text { direita e redução } \\
\text { da flacidez do } \\
\text { canto da boca e } \\
\text { face esquerda, } \\
\text { além da } \\
\text { minimização da } \\
\text { profundidade } \\
\text { das rugas, } \\
\text { clareamento } \\
\text { cutâneo e } \\
\text { melhorando } \\
\text { como um todo o } \\
\text { aspecto, tanto o } \\
\text { grupo tabagista } \\
\text { e no não- } \\
\text { tabagista. }\end{array}$ \\
\hline $\begin{array}{l}\text { A utilização da } \\
\text { radiorequencia no } \\
\text { rejuvenescimento } \\
\text { cutâneo: estudo de } \\
\text { caso. }\end{array}$ & Ponte; Oliveira, (2015) & $\begin{array}{l}\text { Estudo de caso com } \\
\text { abordagem } \\
\text { qualitativa }\end{array}$ & $\begin{array}{l}\text { O objetivo deste } \\
\text { estudo clinica foi } \\
\text { analisar a eficácia } \\
\text { da } \\
\text { radiofrequência na } \\
\text { ação do } \\
\text { rejuvenescimento } \\
\text { cutâneo. }\end{array}$ & $\begin{array}{l}\text { Participaram cinco } \\
\text { sujeitos do sexo } \\
\text { feminino, entre } 48 \\
\text { e } 52 \text { anos. } \\
\text { Apresentavam } \\
\text { fototipo III e IV, } \\
\text { ritides acentuadas e } \\
\text { flacidez moderada } \\
\text { na face. Foram } \\
\text { excluídas da } \\
\text { pesquisa pacientes } \\
\text { que estavam } \\
\text { fazendo dietas e } \\
\text { reeducação } \\
\text { alimentar e que } \\
\text { não faziam a } \\
\text { ingestão de água } \\
\text { moderadamente. }\end{array}$ & $\begin{array}{l}\text { A análise } \\
\text { comparativa } \\
\text { feita através de } \\
\text { foto } \\
\text { documentação } \\
\text { mostrou que } \\
\text { ambos os } \\
\text { tecidos } \\
\text { mostraram } \\
\text { alterações } \\
\text { significativas, } \\
\text { como } \\
\text { diminuição da } \\
\text { flacidez tissular, } \\
\text { viscosidade da } \\
\text { pele e lifting } \\
\text { facial. }\end{array}$ \\
\hline
\end{tabular}

Fonte: Pesquisa do autor 


\section{Discussão}

De acordo com Sousa (2016), as principais características da pele envelhecida são o aumento da rugosidade e a perda da elasticidade, dentre os procedimentos mais usados para o tratamento de rugas e flacidez destaca-se uma terapia não invasiva, a radiofrequência.

Nos artigos coletados, os voluntários a participar dos respectivos estudos que apresentaram contraindicações absolutas para a utilização da radiofrequência (neoplasias, áreas infeccionadas, alterações de sensibilidade, próteses metálicas, gravidez e lactentes) foram excluídos da pesquisa, sendo impedidos de realizar o procedimento. Além disso, foi solicitado que os participantes não realizassem nenhum tratamento medicamentoso que pudesse interferir no estudo, assim como qualquer tratamento facial durante a pesquisa. Busnardo e Azevedo (2012) também excluíram pacientes com telangiectasias na região facial, tabagistas, etilistas e sedentários, sendo essas características dos fatores agravantes para rugas e/ou flacidez.

Silva, Hansen e Sturzenegger (2012) objetivaram avaliar o uso da RF no rejuvenescimento facial. Realizaram uma amostra com 5 voluntárias, com idade entre 35 e 55 anos, primeiramente foi realizada uma anamnese. No início de todas as sessões foram realizadas higienização do rosto. $\mathrm{O}$ rosto de cada voluntária foi divido em 6 zonas designadamente. $\mathrm{O}$ aparelho utilizado foi da marca Spectra, a temperatura da RF foi entre $37^{\circ} \mathrm{C}$ a $40^{\circ} \mathrm{C}$, em cada região selecionada a aplicação foi de três minutos, o procedimento foi finalizado utilizando protetor solar na pele. As sessões foram realizadas semanalmente, cada sessão de 30 minutos, durante cinco semanas. Na comparação dos grupos A (experimental) e B (controle), pôde-se verificar melhora significativa do grupo experimental em relação ao controle, de acordo com os autores as cinco sessões de radiofrequência demonstram melhoras efetivas no estado de flacidez de pele, rugas e linhas de expressão do rosto das voluntárias. Deixando claro que a pele sem nenhum tratamento só tem a regredir ou continuar na mesma situação de envelhecimento. Este fato pode ser justificado devido à atuação profunda do calor da radiofrequência.

Segundo Carvalho (2011), a aplicação da radiofrequência ocorre modelando fibrilas de colágeno e amenizando as rugas da face. $\mathrm{O}$ aumento ou a manutenção, em maiores temperaturas $\left(40^{\circ} \mathrm{C}\right)$, durante todo o período de aplicação da técnica, diminui a extensibilidade e aumenta a densidade do colágeno, resultando, assim, na diminuição da flacidez da pele. 
Pimentel (2013) realizou um estudo no intuito de avaliar um protocolo proposto de rugas periorbiculares através de sessões semanais de RF em idosos, a amostra foi composta por 14 voluntários, com idades entre 60 e 75 anos, sendo os mesmos distribuídos em dois grupos: Grupo Placebo (GP) e Grupo Experimental (GE), contando 07 voluntários em cada um. No primeiro grupo, a intensidade da RF foi 0 (zero) e a aplicação foi de 5 minutos; já no segundo, a intensidade da RF foi 20 amperes, com aplicação de 2 minutos em cada área mantendo temperatura de $41^{\circ} \mathrm{C}$. Nos dois grupos, realizou-se 10 sessões. O aparelho utilizado foi o bipolar, da marca Advice Master.

A avaliação das rugas quanto ao grau de insatisfação pelos voluntários do GE antes do tratamento, variou de moderado a muitíssimo insatisfeito e após o tratamento a reavaliação constatou que o grau de insatisfação variou de pouco a moderado insatisfeito. Já no GP, o grau de insatisfação antes do tratamento variou de pouco a muitíssimo insatisfeito, e após o tratamento o grau de insatisfação variou de não incomodado a muito insatisfeito com as rugas. No que se refere ao grau de satisfação, o GE após o tratamento variou de moderado a ótimo, já o GP relatou o grau de satisfação pouco a bom.

Após a análise estatística verificou que apenas a variável da percepção dos voluntários obteve resultado significativo, todas as outras variáveis, como os registros fotográficos avaliados por examinadores, não apresentaram diferença estatisticamente significantes. A justificativa para uma resposta não significativa pode ser atribuída ao fato de todas as participantes apresentarem mais de 60 anos de idade, corroborando assim com o estudo de Freitas e Waldman (2011) o qual afirma que após a sexta década de vida há uma diminuição da taxa de renovação celular em $50 \%$ e da reparação da pele, diminuindo o colágeno e a elastina que são substâncias fundamental na derme que influência no rugor da pele, sugerindo menor resposta ao tratamento.

No estudo realizado por Busnardo e Azevedo (2012), foi realizada uma amostra com 16 voluntárias, com idade entre 50 e 60 anos, as selecionadas foram divididas em dois grupos, sendo o grupo A experimental e o grupo B de controle. Foram feitas avaliações pré e pós em ambos os grupos através de uma ficha de avaliação facial e fotografias. A RF foi aplicada a uma temperatura entre $38^{\circ} \mathrm{C} \mathrm{e} 40^{\circ} \mathrm{C}$, 1 vez por semana, 40 min. Cada sessão, durante 8 semanas. Verificou-se uma melhora significativa do grupo experimento em relação ao de controle. $\mathrm{O}$ grupo experimental obteve redução das rugas na região orbicular dos olhos e orbicular da boca. 
Através da pesquisa puderam concluir que a radiofrequência é um recurso eficaz quando bem indicado para atenuação e tratamento das rugas e flacidez da face.

Nienkoetter; Helmann e Gonçalves (2012), observaram o efeito da RF da marca CECBRA no tratamento da flacidez facial em dez mulheres com idade entre 35 e 45 anos. As participantes foram avaliadas através de anamnese com avaliação facial, registros fotográficos e questionário de satisfação. As sessões de atendimento começaram com assepsia de toda a face com sabonete líquido, limpeza profunda, gel esfoliante facial e emulsão de limpeza facial, todos da marca Extratos da Terra. A aplicação foi feita com o aparelho de RF de forma direta com gel comum, ajustando a RF de forma de emissão contínua, com potência graduada de acordo com a sensibilidade da paciente. Foi realizada uma sessão semanal, com sete dias de intervalo, totalizando dez sessões de 40 minutos para cada participante. Este estudo concluiu que a intervenção com RF proporcionou redução da flacidez facial, rugas, linha de expressão e melhora na coloração e textura da pele, bem como a satisfação das pacientes.

Os estudos analisados são concordantes em recomendar a higienização da pele antes do o uso terapêutico da RF no tratamento de rugas faciais. Corroborando com Agne (2014), que relata sobre a importância da pele ser higienizada para retirada de resíduos de cosméticos ou hidratantes antes da aplicação da RF, garantindo assim uma melhor eficácia para o tratamento.

Ponte e Oliveira (2015) realizou um estudo de caso onde foi realizado um procedimento que utilizou o aparelho de RF para tratamento do rejuvenescimento cutâneo. Foram realizadas cinco sessões de radiofrequência, com intervalo de 30 dias para a recuperação e regeneração tecidual com o tempo total de vinte minutos em toda a face, o aparelho foi ajustado em 1MHZ, temperatura externa foi mantida em $39^{\circ} \mathrm{C}$ medida através de termômetro por infravermelho, e foi utilizada a técnica de deslizamento no sentido da fibra muscular. A análise comparativa feita através de foto documentação mostrou que ambos os tecidos sofreram alterações significativas, como diminuição da flacidez tissular, viscosidade da pele e lifting facial.

Marchi et al (2016) realizaram um estudo para verificar os efeitos da RF na melhora do aspecto facial geral da pele de indivíduos tabagistas e não tabagistas. Foram realizadas10 sessões de RF em 08 voluntárias do sexo feminino, sendo 04 tabagistas e 04 não-tabagistas, com idade entre 47 e 53 anos. O protocolo de tratamento foi realizado duas vezes por semana, com duração de 25 minutos e amplitude de $80 \%$ até completar 10 sessões, sendo executado da seguinte forma: higienização da pele com sabonete, esfoliação, tonificação e aplicação da RF SPECTRA G1, sendo a aplicação nos parâmetros de amplitude com 80\%, tempo de 25 minutos 
e temperatura de $40^{\circ} \mathrm{C}$, com auxílio de gel de contato Galy Tec, para finalizar o procedimento foi utilizado protetor solar.

Com o resultado houve redução da extensão de rugas do canto externo dos olhos e face direita, redução da flacidez do canto da boca e face esquerda, além da minimização da profundidade das rugas, clareamento cutâneo e melhora como um todo do aspecto, tanto do grupo tabagista e do não- tabagista. Porém eles ressaltam que o estudo não deve ser conclusivo, sugerindo que novas pesquisas, com maior número de sessões, com mais espaçamento entre a realização das sessões e maiores investigações referentes ao tabagismo relacionado ao envelhecimento cutâneo e a ação da radiofrequência sejam realizados.

Passos et al (2008), relata em suas pesquisas que pessoas tabagistas normalmente apresentam rugas em região orbicular de boca e olhos mais evidenciados, sulcos profundos em bochechas, além de uma pele com aparência acinzentada, amarelada, desvitalizada, opaca e normalmente discrômica.

Sousa (2013) realizou um estudo com finalidade de analisar um protocolo de laserterapia associada à radiofrequência para o tratamento de rugas periorbiculares em idosos, a amostra foi constituída por 14 voluntários com idade entre 60 e 70 anos que apresentavam rugas superficiais ou profundas na região periorbicular. Os voluntários foram divididos em dois grupos: experimental e placebo. No grupo placebo foi utilizada a caneta de laserterapia sem emitir energia 0 (zero) joule em cada ponto da extensão das rugas, no grupo experimental foi aplicada a terapia por RF com temperatura de $41^{\circ} \mathrm{C}$ durante dois minutos, e em seguida posicionada a caneta de laserterapia em contato direto com a pele e sendo emitida energia de 3 (joules) em cada ponto de média de extensão das rugas, sendo utilizado em média sete pontos de aplicação na região temporozigomática da face. $\mathrm{O}$ grupo foi atendido duas vezes por semana e submetido a 10 sessões.

Concluiu-se que o protocolo utilizado não demonstrou resultados visuais aceitáveis que o habilitasse com total garantia para ser utilizado no tratamento das rugas periorbiculares em idosos, entretanto, obteve uma percepção dos usuários quanto a melhora das rugas. Recomendase que sejam realizados novos estudos com uma amostra mais homogênea e maior tempo de aplicação do protocolo para que se obtenham resultados mais confiáveis de que o protocolo seja mesmo eficaz no tratamento das rugas visto que os resultados deste estudo foram insuficientes.

A presente revisão verificou que os estudos sobre radiofrequência, aplicada como recurso para tratar as rugas apresentou desfechos favoráveis a sua aplicação. Entretanto, os 
níveis de evidencia dos estudos analisadas são baixos e pode-se observar falta de padronização em termos de equipamentos e parâmetros e a frequência para a aplicação deste método terapêutico. Constatou-se uma limitação de estudos que especifiquem metodologicamente o tema abordado até o momento, o que sucinta a necessidade de novas investigações com desenhos metodológicos específicos.

\section{Conclusão}

Foi possível verificar resultados satisfatórios quanto à radiofrequência no tratamento de rugas. A aplicação da radiofrequência é de suma importância nos tratamentos de disfunções estéticas decorrentes do processo natural de envelhecimento cutâneo, uma vez que resulta na melhoria da flacidez, da aparência e do contorno facial, por agir na derme, causando um aquecimento que leva a reações fisiológicas que promoverão contrações das fibras de colágeno e elastina, estimulando o aparecimento de novas fibras, com melhor qualidade, podendo ser considerado um procedimento seguro e eficaz.

Foi identificado que os estudos que utilizaram o tratamento com radiofrequência durante duas vezes por semana, não obtiveram resultados com significância estatística. Entretanto, houveram estudos com resultados estatisticamente significantes na melhora das rugas e flacidez, com melhora do aspecto visual ou satisfação pessoal, principalmente quando foram utilizados um intervalo de sessões semanal ou mensal. Dessa forma, sugere-se que novas pesquisas sejam realizadas a fim de esclarecer tais questões e ampliar os conhecimentos já existentes.

Estima-se que o presente estudo possa colaborar com a base de conhecimentos já existentes, ajudando na promoção de maiores esclarecimentos aos profissionais que trabalham na área da Fisioterapia Dermato Funcional ou da Estética, facilitando o desenvolvimento de projetos e protocolos que agem de forma preventiva e/ou curativa para o envelhecimento cutâneo facial em questão. 


\section{Referências}

AGNE, J. E. Eletrotermoterapia. $1^{\circ}$ Santa Maria: o autor 2014.

BORGES, Fábio dos Santos. Dermato-funcional: modalidades terapêuticas nas disfunções estéticas. 2 ed, São Paulo: Phorte, p.607, 2010.

BUSNARDO, V.L; AZEVEDO, M.F. Estudo dos efeitos da radiofrequência no tratamento facial em mulheres entre 50 e 60 anos de idade, 2012.

CARVALHO, G.F; SILVA, R.M.V. Avaliação dos Efeitos da Radiofreqüência no Tecido Conjuntivo.Especial Dermatologia, v.3, n.68, p.10-25, 2011.

FONTOURA, Gabriela Amaral.Os efeitos da endermoterapia no fotoenvelhecimento facial.Universidade do extremo sul catarinense, SC, Nov 2009.

MACEDO, Monique Costa Almeida; Tenório Caroline Amaral. Tratamento de rugas: Uma revisão bibliográfica sobre Carboxiterapia, Radiofrequência e Microcorrente. Visão universitária, Cassilândia, Brasil - MS, P.54/78, 2015.

MACHADO, Rosiléa M. L.; Cavaliére,Stelamaris L. O envelhecimento e seus reflexos Biopsicossociais. Cadernos Unisuam. RJ. V.2, n.1, p. 110/120, jun. 2010.

MARCHI, J.P; ROCHA, K. G.P; SEVERO, P. V. A; BRUNING, M. C. R; LOVATO, E. C. W. Arq. Ciência saúde, UNIPAR, SP. Mai- ago,2016.

MENDES, K. D. S.; SILVEIRA, R. C. C. P.; GALVÃO, C. M. Revisão integrativa: método de pesquisa para a incorporação de evidências na saúde e na enfermagem integrative literature. Texto \& Contexto Enferm, Florianópolis, v. 17, n. 4, p. 758-764, out/dez, 2008.

PASSOS, C. dos et al. Efeitos do tabagismo no envelhecimento cutâneo. 2008. 15 f. Artigo de conclusão de curso (Curso Superior de Tecnologia em Cosmetologia Estética) Universidade do Vale do Itajaí - Balneário

Comburiu, 2008.

PIMENTEL, T.T.S. Radiofrequência aplicada em rugas periorbiculares: avaliação de um novo protocolo. Campina Grande- Paraíba, 2013.

PONTE, A. P; OLIVEIRA, S. P. A Utilização da Radiorequência no Rejuvenescimento Cutâneo: Estudo de Caso. Universidade Tuiutu do Paraná- PR, 2015.

SANTOS, Maria Luiza Paulo; SANTIS, Simone de Almeida Cosmo. O processo de envelhecimento cutâneo e suas diferenças entre a pele branca e a negra, associado a dois fatores distintos: $\mathrm{O}$ envelhecimento intrínseco e extrínseco. Universidade Tuiuti do Paraná PR, p. 5/9, 2015. 
SILVA, M.V.R; HANSEN, D; STURZENEGGER, T.M. Radiofrequência no Rejuvenescimento Facial. Rio Grande do Sul, 2012.

SOUSA, Julianna Neves; Ouso da diatermia por radiofrequência no tratamento das rugas e flacidez facial: Revisão bibliográfica, Universidade federal da Paraíba, 2016.

SOUSA, Caroline de Medeiros Lima. Análise de um protocolo de laserterapia de baixa potência e radiofrequência no tratamento de rugas em idosos.(trabalho de conclusão de curso).Universidade Estadual da Paraíba, 2013.

SOUZA, Soraya. L.G.et al. Recursos fisioterapêuticos utilizados no tratamento do envelhecimento facial. Revista Fafibe online, Bebedouro - SP, n.3, ago 2007.

TESTON, Ana Paula; NARDINO, Deise; PIVATO, Leandro. Envelhecimento Cutâneo: Teoria dos radicais livres e tratamento visando à prevenção e o rejuvenescimento. Revista UNINGÁ Review, Maringá - PR, n 1, p.71/84, jan 2010.

\section{Como citar este artigo (Formato ABNT):}

SILVA, Patriciana R da; ANDRADE, Adna G.F.; FACCHINETTI, Juliana B. Radiofrequência no Tratamento de Rugas: Uma Revisão Integrativa. Id on Line Revista ultidisciplinar e de Psicologia, 2017, vol.12, n.39, p.44-57. ISSN: 1981-1179.

Recebido: 13.11 .2017

Aceito: 14.11.2017 